\title{
The optimal recording electrode configuration for compound sensory action potentials
}

\author{
EMMANUEL EDUARDO,* DAVID BURKE \\ From the Unit of Clinical Neurophysiology, Department of Neurology, The Prince Henry Hospital and School of \\ Medicine, University of New South Wales, Sydney, Australia
}

SUMMARY There is no uniformity in the published literature from different laboratories on the optimal electrode configuration for recording nerve action potentials, and a number of standard texts omit any reference to the effects that interelectrode distance and electrode orientation can have on the shape, amplitude and latency of nerve action potentials. The sensory action potential from the digital nerves of the index finger was recorded at wrist and elbow using bipolar electrodes with the "active" electrode over the median nerve and the "reference" placed $4 \mathrm{~cm}$ laterally or proximally along the nerve using interelectrode distances of 4,3 and $2 \mathrm{~cm}$. These potentials were compared with that recorded using a remote reference on the ipsilateral shoulder, the assumption being that this configuration eliminated the contribution of the reference electrode to the compound nerve action potential. With different electrode configurations, there were significant differences in the shape of the potential, the latencies to onset and peak and the rising- and falling-phase amplitudes. The shorter the distance between the electrodes the greater the distortions. Overall, the distortions were least with the $4 \mathrm{~cm}$ interelectrode separation, particularly for short conduction distances.

Although there has been much debate in the evoked potential literature about the optimal recording montages for somatosensory evoked potentials, relatively few studies have considered recording parameters for nerve action potentials. ${ }^{1-4}$ Relevant chapters in many standard references do not discuss electrode configuration $^{5-10}$ (however see ref. 11), and there appears to be no unanimity on usage between different laboratories. For example, recent publications have used or recommended the following interelectrode distances: $4 \mathrm{~cm}$ for antidromic and $2 \mathrm{~cm}$ for orthodromic recordings; ${ }^{12} 1 \mathrm{~cm}$ for antidromic and 3 $\mathrm{cm}$ for orthodromic recordings, ${ }^{13} 2 \mathrm{~cm}$ for antidromic recordings, ${ }^{14} 2-3 \mathrm{~cm},{ }^{15} 163 \mathrm{~cm}$ for orthodromic recordings ${ }^{17}$ and $3.5 \mathrm{~cm}$ for orthodromic recordings. ${ }^{18}$ Furthermore, while most authorities measure latencies to the onset of the negative phase of the compound action potential, others quote latencies

*Present address: Department of Clinical Neurosciences, UERM Memorial Medical Centre, Quezon City, The Philippines.

Address for reprint requests: David Burke, MD., D.Sc., Unit of Clinical Neurophysiology, The Prince Henry Hospital, PO Box 233, Matraville, Sydney, NSW 2036, Australia.

Received 1 December 1987

Accepted 5 January 1988 to the negative peak (for example refs $12,19,20-22$ ); some measure the amplitude of the negative phase, but others quote peak-to-peak amplitudes (such as in refs 22,23 ).

The implication in diagnostic studies is always that the recorded action potential reflects activity seen at the "active" electrode. This assumption is reasonable only if the contribution of the "reference" electrode is negligible, an unlikely assumption with a bipolar recording, no matter what the electrode orientation. The present study was undertaken to quantify the effects of different "reference" electrode positions on orthodromic nerve action potentials. Although a number of other studies have documented differences in the shape and amplitude of compound sensory action potentials with different longitudinal interelectrode distances ${ }^{13}$ and with longitudinally and transversely orientated references, ${ }^{24}$ no previous study has attempted to compare these potentials with that which would be recorded if a true monopolar derivation were possible.

\section{Methods}

The study was performed on six healthy volunteers with no past history of neuromuscular disease, each of whom gave informed consent to the procedures. The orthodromic sen- 
$4 \mathrm{~cm}$ Bipolar reference

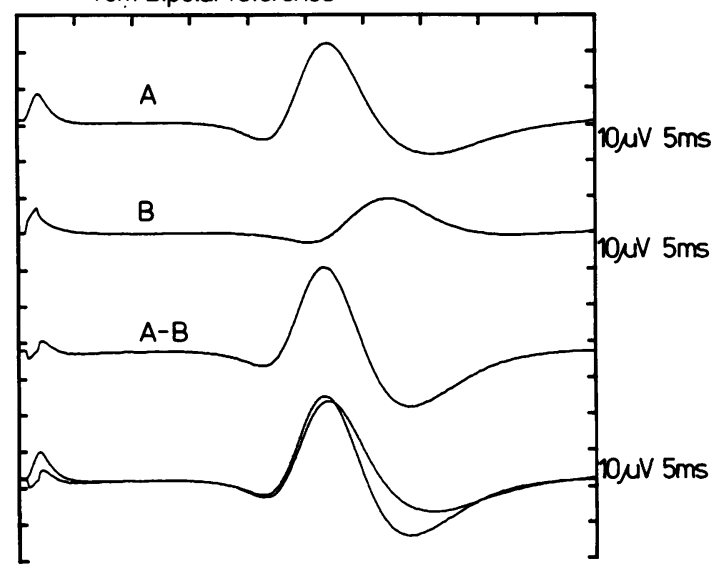

Fig 1 Comparison between potentials recorded with a remote reference and with $4 \mathrm{~cm}$ bipolar electrodes. Trace $(A)$ : potential recorded from the conventional active site at the wrist using a remote reference. Trace $(B)$ : potential recorded by an electrode $4 \mathrm{~cm}$ proximal to the conventional active site using a remote reference. Trace $(A-B): 4 \mathrm{~cm}$ bipolar reconstructed by subtracting trace $B$ from trace $A$. Fourth trace: superimposition of the first and third traces. Each trace is the average of 256 sweeps. Vertical scale: 10 $\mu V /$ div; Horizontal scale: $0.5 \mathrm{~ms} /$ div.

sory action potential produced by stimulating the digital nerves of the index finger was recorded from the median nerve at the wrist or elbow using subdermal platinum-alloy needle electrodes with a bared tip of $3 \mathrm{~mm}$. Constant-voltage rectangular pulses of duration $0 \cdot 1 \mathrm{~ms}$ were delivered at $2 \mathrm{~Hz}$ to the index finger through ring electrodes around the proximal phalanx. The stimulus intensity was set at three times threshold and was supramaximal for the evoked compound sensory action potential. Limb temperature was monitored throughout each experiment and was maintained constant at more than $32^{\circ} \mathrm{C}$.

At the wrist or, in separate experiments, at the elbow, the compound sensory action potential was recorded simultaneously from five sites using a remote reference at the ipsilateral shoulder. The bandwidth for each recording channel was $0.3 \mathrm{~Hz}$ to $1.5 \mathrm{kHz}$. Routinely 256 responses were averaged using a sampling rate of $50 \mathrm{kHz}$. The first recording electrode was situated along the course of the median nerve at the wrist, $2 \mathrm{~cm}$ proximal to the distal crease (conventional active site). The other electrodes were placed $4 \mathrm{~cm}$ lateral and $2 \mathrm{~cm}, 3 \mathrm{~cm}$ and $4 \mathrm{~cm}$ proximal to this conventional site. Bipolar recordings with $4 \mathrm{~cm}, 3 \mathrm{~cm}$ and $2 \mathrm{~cm}$ interelectrode distances were reconstructed by subtracting the waveform recorded by the relevant electrode from that recorded at the conventional site (see figs 1 and 3). A similar procedure was used to reconstruct the potential seen with a reference $4 \mathrm{~cm}$ lateral to the conventional site (see fig 2). The reconstructed potentials were then compared with that recorded from the conventional site using the shoulder reference (see fourth traces in figs 1 and 2). In control experiments it was confirmed that, as must be, the "reconstructed" potentials were identical to those recorded using bipolar inputs.

The latency, amplitude and duration of the recorded and reconstructed potentials were measured. Latencies were measured to the peak of the first positive deflection or, if this was absent, to the onset of the negative deflection (onset latency) and to the peak of the subsequent negative deflection (peak latency). Amplitudes were measured peakto-peak for both the rising and falling phases of the potential. Duration was determined by measuring the time between the peak of the first positive deflection to the peak of the second positive deflection. On some occasions, particularly at the elbow, a second positive peak could not be defined, and the point at which the potential returned to the baseline was used. The above-mentioned parameters for the reconstructed potentials were expressed as a percentage of the values for that subject for the potential recorded from the conventional site using the remote reference on the shoulder. The significance of differences from these control values was assessed using a paired $t$ test.

\section{Results}

The potential recorded at the wrist or elbow against a remote reference on the shoulder is considered in this study to reflect the activity seen by the "active" electrode and, in bipolar derivations, deviations from this to represent unwanted distortions due to the "reference" electrode. This assumes that there are no significant "far-field" contributions to the recorded activity within the relevant time interval, ${ }^{24}$ an

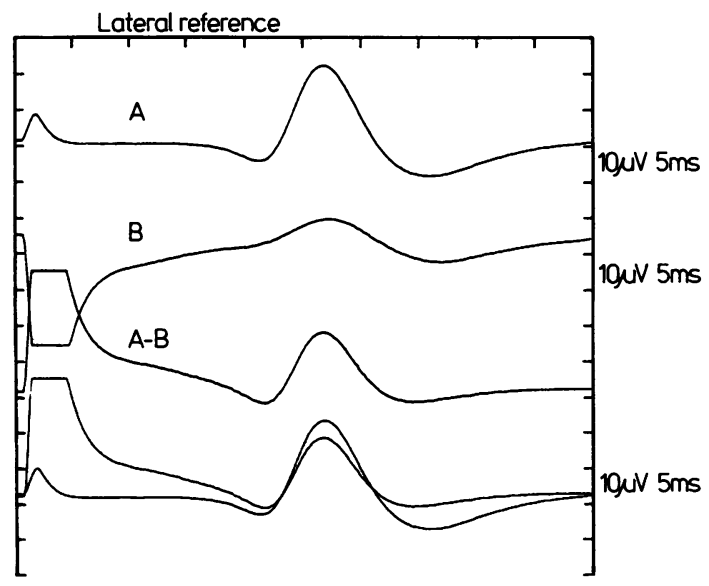

Fig 2 Comparison between potentials recorded with a remote reference and a lateral reference. Trace $(A)$ : potential recorded from the conventional site at the wrist using a remote reference. Trace $(B)$ : potential recorded by an electrode $4 \mathrm{~cm}$ lateral to the conventional site using $a$ remote reference. Trace $(A-B)$ : laterally referred potential reconstructed by subtracting trace $B$ from trace $A$. Fourth trace: superimposition of traces $(A)$ and $(A-B)$. Each trace is the average of 256 sweeps. Vertical scale: $10 \mu \mathrm{V} /$ div; Horizontal scale: $0.5 \mathrm{~ms} /$ div. 


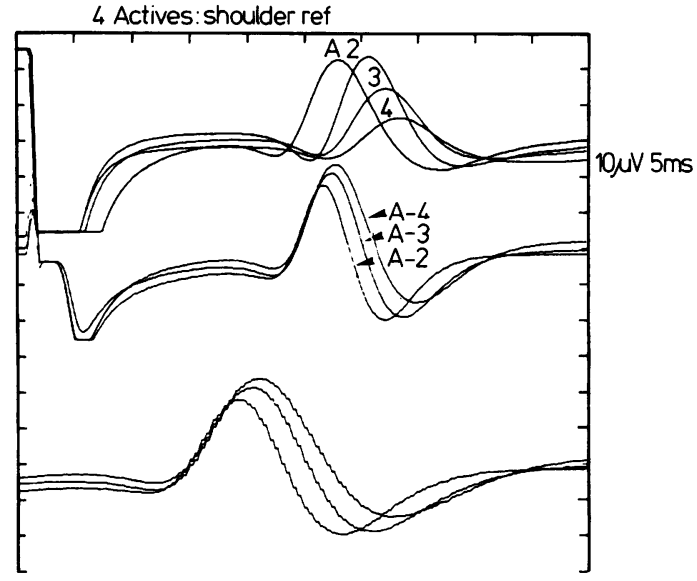

Fig 3 Bipolar recordings using three different interelectrode distances. Top trace: recordings from conventional active site ( $A$ ) and from $2 \mathrm{~cm}(2), 3 \mathrm{~cm}$ (3) and $4 \mathrm{~cm} \mathrm{(4)} \mathrm{proximal} \mathrm{to} \mathrm{the} \mathrm{conventional} \mathrm{active} \mathrm{site,} \mathrm{using}$ a shoulder reference. Second trace: reconstructed bipolar recordings with interelectrode distances of $4 \mathrm{~cm}(A-4), 3 \mathrm{~cm}$ $(A-3)$ and $2 \mathrm{~cm}(A-2)$. Lowest trace: same as second trace but with expanded time base. Each trace is the average of 256 sweeps. Vertical scale: $10 \mu \mathrm{V} /$ div; Horizontal scale: $0.5 \mathrm{~ms} /$ div (for top and middle traces only).

assumption that is probably valid for orthodromic recordings at the wrist, but may be debated for recordings at the elbow. ${ }^{25} 26$ As it happened, the compound nerve action potentials proved to be clean potentials not obviously contaminated by "far-field" activity, and this factor will not be considered further.

Compound nerve action potential at the wrist All reference electrodes saw a significant neural volley (figs $1-3$ ), on average $31 \%, 41 \%, 59 \%$ and $75 \%$ of that seen by the "active" electrode for the lateral, $4 \mathrm{~cm}, 3$ $\mathrm{cm}$ and $2 \mathrm{~cm}$ references, respectively. As a result there were significant distortions of shape, latency and amplitude in the bipolar recordings. The distortions of shape are illustrated in figs 1-3 and are identical to those documented by Andersen. ${ }^{4}$ The latency data are summarised in table 1, and the amplitude data in the table 2 .

There were no significant deviations from the
Table 2 Rising-and falling-phase amplitudes

\begin{tabular}{|c|c|c|c|c|c|c|}
\hline \multirow[b]{2}{*}{ Reference } & \multicolumn{3}{|c|}{ Rising phase } & \multicolumn{3}{|c|}{ Falling phase } \\
\hline & Mean & $S D$ & $p$ & Mean & $S D$ & $p$ \\
\hline $\begin{array}{l}\text { Lateral } \\
2 \mathrm{~cm} \\
3 \mathrm{~cm} \\
4 \mathrm{~cm}\end{array}$ & $\begin{array}{r}76 \% \\
84 \% \\
97 \% \\
101 \%\end{array}$ & $\begin{array}{r}4 \% \\
11 \% \\
9 \% \\
7 \%\end{array}$ & $\begin{array}{l}<0.001 \\
<0.001 \\
=0.560 \\
=0.645\end{array}$ & $\begin{array}{r}65 \% \\
119 \% \\
136 \% \\
138 \%\end{array}$ & $\begin{array}{r}7 \% \\
12 \% \\
12 \% \\
12 \%\end{array}$ & $\begin{array}{l}<0.001 \\
<0.001 \\
<0.001 \\
<0.001\end{array}$ \\
\hline
\end{tabular}

"true" latencies with the $4 \mathrm{~cm}$ configuration. With the lateral reference, latencies to onset were significantly longer $(\mathrm{p}<0.005)$ than the "true" value, but with the $2 \mathrm{~cm}$ and $3 \mathrm{~cm}$ montages they were significantly shorter ( $p<0.02$ and 0.01 respectively). With these two montages, latencies measured to the negative peak of the potential were more severely affected than those to onset. Rising-phase amplitudes were less distorted than falling-phase amplitudes and, again, the least amplitude distortion occurred with the $4 \mathrm{~cm}$ montage. With each recording montage, the duration of the potential deviated significantly from the "true" duration ( $\mathrm{p}<0.001$ for each montage; see table 1). Compound nerve action potential at the elbow. In three subjects, recordings were made at the elbow to model the effects of greater dispersion of the neural volley, as would occur with a long conduction dis tance or with pathological dispersion over a shorf conduction distance. The recorded potentials were biphasic with the remote and lateral references, buto triphasic with the $3 \mathrm{~cm}$ and $4 \mathrm{~cm}$ references. Latencies to onset were longer than the "true" value $(101 \cdot 1 \%)$ with the lateral reference, shorter $(98.5 \%)$ with the 3 $\mathrm{cm}$ reference and similar $(99.4 \%)$ with $4 \mathrm{~cm}$ reference. Rising-phase amplitudes were smaller than the "true" value: $88 \%$ with the lateral references, $82 \%$ with the $4 \mathrm{~cm}$ reference, $68 \%$ for the $3 \mathrm{~cm}$ reference. The duration of the potential was $79.6 \%$ of the "true" value with the lateral reference but only $40.3 \%$ and $36.7 \%$ with the $4 \mathrm{~cm}$ and $3 \mathrm{~cm}$ references, respectively.

\section{Discussion}

This study has demonstrated significant contributions of the reference electrode with all four recording montages, the degree of distortion of the "true" neural volley being least with electrodes $4 \mathrm{~cm}$ apart, orien-

Table 1 Latency and duration

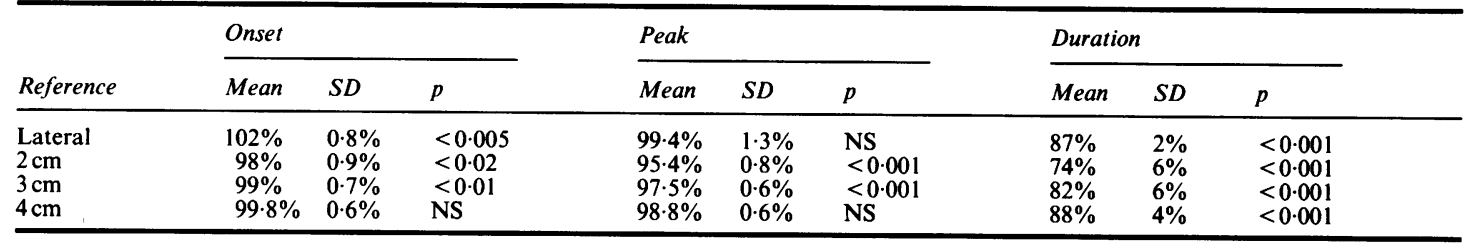


tated longitudinally along the nerve. Undoubtedly the distortions would have been even less had a longer interelectrode distance been studied but, in routine use, there could then be more noise in the recording and the saddle necessary to carry the surface electrodes would be more cumbersome. Gilliatt and colleagues $^{1}$ and Andersen ${ }^{4}$ compared potentials recorded with different bipolar montages and, inevitably, many of their findings are similar to the present. However, the present study was predicated on comparison of bipolar recordings with the potential that would be recorded by the "active" electrode in isolation, if a true monopolar recording were possible, and this presumably allows more accurate definition of the contribution of the reference electrode in each bipolar derivation.

With electrodes orientated along the nerve, the distortions of latency are relatively small, even if significant, when latency is measured to the onset of the negative phase (equivalent to an "error" in conduction velocity of $<1.5 \mathrm{~m} / \mathrm{s}$ ). However the progressive loss of the initial positive deflection with the shorter interelectrode distance (see fig 3) could make measurement difficult with pathologically small potentials. The contribution of the reference recording is, not surprisingly, greater with latencies measured to the peak of the negative phase and with falling-phase amplitudes. In clinical practice, such measures should not be used without appreciation that the recorded potential contains significant activity not generated at the supposedly "active" electrode. With "inching" techniques and the use of short interelectrode distances, precise localisation of an abnormality depends on both electrodes, not just the supposedly "active" one of the pair.

The present findings emphasise the need to avoid variations in electrode separation, as can occur when surface electrodes are individually taped to the skin rather than fixed in a saddle that is strapped to or held against the limb. A laboratory may maintain internal consistency whichever montage it chooses provided that the same montage is always used and that normal values were obtained with that montage. However, it may be difficult to compare results between laboratories if the recording montages are not specified. Finally, the more dispersed a neural volley, the more the reference will affect the recorded potential, particularly when the electrodes are orientated longitudinally along the nerve trunk.

This study was supported by the National Health \& Medical Research Council of Australia. The authors are grateful to Drs JW Lance and AK Lethlean for support and advice and to Mr NF Skuse for technical assistance.

\section{References}

1 Gilliatt RW, Melville ID, Velate AS, Willison RG. A study of normal nerve action potentials using an averaging technique (barrier grid storage tube). J Neurol Neurosurg Psychiatry 1965;28:191-200.

2 Buchthal F, Rosenfalck A. Evoked action potential and conduction velocity in human sensory nerves. Brain Res 1966;3:1-122.

3 Varghese G, Rogoff J. Influence of interelectrode distance on sensory potentials. Electromyogr Clin Neurophysiol 1983; 23:297-301.

4 Andersen $K$. Surface recording of orthodromic sensory nerve action potentials in median and ulnar nerves in normal subjects. Muscle Nerve 1985;8:402-8.

5 Gilliatt RW. Nerve conduction: motor and sensory. In Licht S, ed. Electrodiagnosis and Electromyography, 2nd edition. New Haven: Licht, 1961:385-411.

6 Goodgold J, Eberstein A. Electrodiagnosis of Neuromuscular Diseases. Baltimore: Williams and Wilkins, 1972.

7 Daube JB. Nerve conduction studies. In: Aminoff MJ, ed. Electrodiagnosis in Clinical Neurology, 1st edition. New York: Churchill-Livingstone, 1980:229-64.

8 Stålberg E, Young RR, eds. Clinical Neurophysiology. Boston: Butterworths, 1981.

9 Kimura J. Electrodiagnosis in Diseases of Nerve and Muscle: Principles and Practice. Philadelphia: FA Davies, 1983.

10 Halliday AM, Butler SR, Paul R. A Textbook of Clinical Neurophysiology. New York: John Wiley \& Sons, 1987.

11 Brown WF. The Physiological and Technical Basis of Electromyography. Boston: Butterworths, 1984.

12 Melvin JL, Harris DH, Johnson EW. Sensory and motor conduction velocities in the ulnar and median nerves. Arch Phys Med Rehabil 1966;47:511-9.

13 Murai Y, Sanderson I. Studies of sensory conductions. Comparison of latencies of orthodromic and antidromic sensory potentials. J Neurol Neurosurg Psychiatry 1975;38:1187-9.

14 Kimura J, Ishida T, Suzuki S, Kudo Y, Matsuoka H, Yamada T. Far-field recording of the junctional potential generated by median nerve volleys at the wrist. Neurology 1986;36:1451-7.

15 Cohen HL, Brumlik J. Manual of Electroneurography, 2nd ed. New York: Harper and Row, 1976.

16 Smorto MP, Basmajian JV. Electrodiagnosis: A Handbook for Neurologists. New York: Harper and Row, 1977.

17 Lenman JAR, Ritchie AE. Clinical Electromyography. 3rd ed. London: Pitman Press, 1983.

18 Levin K, Stevens C, Daube J. Superficial peroneal nerve conduction studies for electromyographic diagnosis. Muscle Nerve 1986;9:322-6.

19 Walsh JC, McLeod JG. Alcoholic neuropathy: an electrophysiological and histological study. J Neurol Sci 1970; 10:457-69.

20 Walsh JC, Yiannikas C, McLeod JG. Abnormalities of proximal conduction in acute idiopathic polyneuritis: comparison of short latency evoked potentials and F-waves. J Neurol Neurosurg Psychiatry 1984;47:197-200.

21 Chodoroff G, Tashjian EA, Ellenberg MR. Orthodromic vs antidromic sensory nerve latencies in healthy persons. Arch Phys Med Rehabil 1985;66:589-91.

22 Jamal GA, Weir AL, Ballantyne JP. The neurophysiologic investigation of small fiber neuropathies. Muscle Nerve 1987;10:537-45.

23 Iyer KS, Kaplan E, Goodgold J. Sensory nerve action potentials of the medial and lateral plantar nerve. Arch Phys Med Rehabil 1984;65:529-30.

24 Kimura J, Mitsudome A, Yamada T, Stokes Dickins Q. Stationary waves from a moving source in far-field recording. Electroencephalogr Clin Neurophysiol 1984;58:351-61.

25 Kimura J, Machida M, Ishida T, et al. Relation between size of compound sensory or muscle action potentials, and length of nerve segment. Neurology 1986;36:647-52.

26 Frith RW, Benstead TJ, Daube JR. Stationary waves recorded at the shoulder after median nerve stimulation. Neurology 1986;36:1458-64. 